\title{
Social media strategies: Understanding the differences between North American police departments
}

\author{
Albert Meijer ${ }^{a}$, Marcel Thaens ${ }^{b}$ \\ a Utrecht University, Bijlhouwerstraat 6, 3511 ZC Utrecht, Netherlands \\ ${ }^{\mathrm{b}}$ Erasmus University Rotterdam, Netherlands
}

\section{A R T I C L E I N F O}

Available online 20 November 2013

Keywords:

Social media

Transformational capacities

Emergent strategies

Police departments

\begin{abstract}
A B S T R A C T
Within a short timeframe, social media have become to be widely used in government organizations. Social media gurus assume that the transformational capacities of social media result in similar communication strategies in different organizations. According to them, government is transforming into a user-generated state. This paper investigates this claim empirically by testing the claim of convergence in social media practices in three North-American police departments (Boston, Washington DC and Toronto). The research shows that the social media strategies are widely different: the Boston Police Department has developed a 'push strategy' while the Metropolitan Police Department in DC has developed a 'push and pull strategy and the Toronto Police Service a 'networking strategy'. The paper concludes that a combination of contextual and path-dependency factors accounts for differences in the emerging social media strategies of government organizations. Social media have a logic of their own but this logic only manifests itself if it lands on fertile soil in a government bureaucracy.
\end{abstract}

(c) 2013 Elsevier Inc. All rights reserved.

\section{Introduction}

Social media hold the promise of increasing the effectiveness and legitimacy of the public sector by facilitating communication and coordination between a variety of internal and external stakeholders (Bertot, Jaeger, \& Grimes, 2010; Choon \& Luna Reyes, 2012; Hrdinová, Helbig, \& Peters, 2010; Kavanaugh et al., 2012; Ma, 2013). Police departments all around the world have acknowledged this potential and are experimenting with a variety of applications. Social media are being used to enhance citizens' input in police investigations, to strengthen the public image of police departments, to control crowds, to tackle crisis situations, to obtain better input in policy-making processes and to attract new police officers.

Attractive as the use of social media may be, effective implementation is neither trivial for corporate organizations (Mergel, Mugar, \& Hossein Jarrahi, 2012) nor for government organizations (Meijer, Koops, Pieterson, Overman, \& Ten Tije, 2012). Mergel (2012: 284) points out that especially the latter are facing the dilemma of innovating their digital interactions using social media outlets within the existing hierarchical settings: 'The potential of social media use for meaningful, multi-directional exchanges between government and its diverse audiences do not fit the highly regulated and practiced top-down decisionmaking and broadcasting culture'. According to Picazo-Vela, GutierrezMartinez, and Luna-Reyes (2012), a social media strategy is necessary to realize the benefits and to avoid risks associated with social media

E-mail addresses: a.j.meijer@uu.nl (A. Meijer), thaens@fsw.eur.nl (M. Thaens). applications. Social media strategies often do not take the form of formal strategic plans but emerge out of a series of choices of officials in different positions in organizations (Mergel, 2012: 290). The strategies take the form of technological choices regarding the coupling of social media to a set of organizational tasks, the range of objectives that are thought to be attained by the use of social media and the organizational arrangements in the form of tasks and responsibilities for social media management.

Social media advocates highlight the transformational capacities of social media and there is some evidence that the social media 'logic' indeed facilitates certain practices and therefore steers communication strategies of different organizations in the same direction (Deibert, 1997; DiMaggio \& Powell, 1983). At the same time, other evidence suggests that new media are adapted to the specific situation and that patterns of new media use reflect underlying organizational and institutional differences (Fountain, 2001; Mergel et al., 2012; Orlikowski, 1992). Our research aims to enhance our understanding of the transformational capacities of social media by studying emerging strategies of public organizations.

The empirical domain of policing is distinct from the rest of the public sector but makes for an interesting domain of study due to variety in citizens' contacts and the diversity in forms of communication. The central research question in this paper is: do police departments develop similar or different social media strategies and how can similarities or differences be explained? The paper will build upon theoretical notions about social media, (emerging) strategies and policy convergence/ divergence. The empirical research concerns an in-depth analysis of social media strategies in three large North-American police departments 
(Boston, Washington DC and Toronto). The results from these case studies are used to shed light on the transformational capacity of social media.

\section{Social media strategies}

The term social media - or Social Networking Sites (SNS) - is used for a group of new technologies such as Twitter, YouTube and Facebook that have been argued to form a new generation of internet technologies (Web 2.0) (Dadashzadeh, 2010; Meijer \& Thaens, 2010). More specifically, these technologies form the fifth wave of ICT adoption in government after mainframes in the 1950s and 1960s, central timeshare systems in the 1970s and 1980s, minicomputers and LAN in the 1980 and 1990s and online e-services in the 1990s and 2000s (Bretschneider \& Mergel, 2010). Bertot, Jaeger, and Grimes (2012) and Bertot, Jaeger, and Hansen (2012) highlight that the term social media refers to a set of online tools that are designed for and centered around social interaction. These new technologies are different from the previously dominant information websites in the sense that they provide platforms for interactions between users and these users engage in a variety of interactions to obtain the information they are specifically interested in. A systematic overview of the differences between social media and information websites is presented in Table 1.

Interestingly, these features do not make social media much different from older technologies such as the Usenet and Mailing Lists. These 'old technologies' seem to fit most of these criteria since it is also about content provision by users through many-to-many networks. The only reason they may not qualify as a social medium is that Usenet and Mailing Lists offer few options to personalize information. Overall, we would argue that social media are not something new but should rather be understood as a new version of the original internet.

Social media have been developed for the consumer market but for various reasons they are also useful to organizations in the public sector. They are cheap, easy and fast and therefore attractive as a means to strengthen the external media mix. Snead (2013) points out that in the U.S. the use of social media applications within government was stimulated by the Open Government Directive of the Obama administration. This directive requires agencies to increase the amount of government information in their websites and to use mechanisms that encourage the public to identify useful and wanted types of information. The directive also requires agencies to use mechanisms in websites to solicit public feedback and public knowledge capable of improving government effectiveness and efficiency. In addition, the directive includes using mechanisms to inform the public about agency activities, operational information, and management decisions. To address the directive, many agencies adopted social media applications (Snead, 2013).

The use of social media involves a series of practical decisions such as what medium is to be used, what kind of information is to be provided through this medium, who is going to provide the information, and what will the organization do with reactions. In more formal organizational terms, these choices involve the following issues: (1) technological choices regarding social media, (2) the coupling of social media to a set of organizational tasks, (3) the identification of a range of objectives that are to be attained by the use of social media and (4) a set of organizational arrangements in the form of tasks and responsibilities for social media management and use (see also Wigand, 2011). The combinations of choices on these four dimensions can be conceptualized as a social media strategy.

Table 1

Differences between information websites and social media.

\begin{tabular}{lll}
\hline & Information websites & Social media \\
\hline Content provider & Organizational content & User-generated content \\
Network topology & One-to-many & Many-to-many \\
Information specificity & General information & Personalized information \\
\hline
\end{tabular}

Research on the adoption process of social media in government shows that organizations apply different strategies (see Table 2). The first type of strategy is a 'push strategy' in which social media are predominantly used to broadcast existing web content out through the additional social media channels (Mergel, 2012). This type of use is similar to the use of mass media: there is no interaction and social media are used to broadcast information. The second type of strategy is a 'pull strategy'. The organization uses social media to attract users to the website and to have them provide new information. In this way government agencies are slowly trying to pull information in from citizens through social media channels while there is a limited level of interaction since the organization hardly responds to these comments (Mergel, 2012). A third strategy is the 'networking strategy'. Mergel (2010: 10): 'The use of social media tools is highly interactive with a lot of back and forward between the agency and its diverse constituencies.' Within this strategy government agencies allow themselves to actively (or passively) participate in actual networking and interactive engagement. A final tactic or strategy is one in which government services are conducted through social media applications: social media is then used for actual transactions between organization and citizens. Mergel (2012: 283) concludes however, that this fourth strategy is 'rarely observable' at this moment.

These strategies consist of a series of choices regarding the use of the technology and its embedding in organizational tasks, objectives and arrangements. The push and pull strategies tend to have more centralized arrangements for a limited set of tasks and public relations as the main objective. The networking strategy and the strategy in which actual services are conducted are more decentralized, more directly connected to a variety of tasks and with a variety of objectives.

Conventional notions of organizational strategy refer to the idea of a strategic plan that explicitly states which instruments are to be used to realize certain long-term perspectives (Porter, 1980). This conventional notion has been criticized for not acknowledging that many strategic actions are at least partially unplanned (Chaffee, 1985). The notion of an unplanned strategy has been developed in detail by Mintzberg (1978: 934) who broadened the definition of strategy to 'a pattern in a stream of decisions'. This means that a strategy is not to be found in formal documents but in practices in organizations and cognitions of organizational members. Mintzberg and Waters (1985) highlight that an emerging strategy - in contrast with a deliberate strategy - consists of patterns or consistencies realized despite, or in the absence of, intentions. This perspective provides a richer understanding of strategy and seems particularly useful for studying fast changing technological practices.

\section{Do social media have a transformative potential?}

Much of the literature on ICT, or more specifically social media, suggests that these technologies have a certain logic and this logic will have a transformational effect on government (Dadashzadeh, 2010; Landsbergen, 2010). Leadbeater and Cottam (2009) refer to the idea of the 'user-generated state' and argue that the platform character of the new media will fundamentally change the nature of relations between

Table 2

Social media strategies (based on Mergel, 2012).

\begin{tabular}{|c|c|c|}
\hline Type of strategy & $\begin{array}{l}\text { Perspective on } \\
\text { government-citizen relations }\end{array}$ & Role of social media \\
\hline Push strategy & $\begin{array}{l}\text { Citizens as audience } \\
\text { for government information }\end{array}$ & $\begin{array}{l}\text { Social media as } \\
\text { broadcasting channel }\end{array}$ \\
\hline Pull strategy & $\begin{array}{l}\text { Citizens as sensors } \\
\text { for government }\end{array}$ & $\begin{array}{l}\text { Social media as channel } \\
\text { for citizen input }\end{array}$ \\
\hline Networking strategy & $\begin{array}{l}\text { Citizens as coproducers } \\
\text { of government policies }\end{array}$ & $\begin{array}{l}\text { Social media as } \\
\text { interactive channel }\end{array}$ \\
\hline Transaction strategy & $\begin{array}{l}\text { Citizens as business partners } \\
\text { of government }\end{array}$ & $\begin{array}{l}\text { Social media as } \\
\text { transactional environment }\end{array}$ \\
\hline
\end{tabular}


government and citizens. Eggers (2005) states that technology helps government to transform itself into a 'citizen-centered government'. These ideas rely on a techno-deterministic perspective on sociotechnological processes: they assume that the use of technology changes or even transforms social practices. The best known proponent of this perspective is Marshall McLuhan (1964) who argued that 'the medium is the message'. He highlighted that the use of new media fundamentally changes our cognitions and practices. A more contemporary version of McLuhan's work can be found in the idea of 'media affordances' (Deibert, 1997). This theory highlights that media characteristics may not determine its actual use but they do make certain practices more attractive than others and, consequently, may result in a homogeneous transformation of strategies.

Other authors have questioned this perspective and highlight that technology is used in many different ways. Technology creates certain opportunities but how these opportunities are used depends on the individual or organization that decides to use it. A prominent version of this socio-deterministic argument is the reinforcement thesis that reads that existing values and power distributions are reproduced in the use of new technologies (Danziger, Dutton, Kling, \& Kraemer, 1982; King \& Kraemer, 2012; Kraemer \& King, 2006). The decision-makers will put the new technologies to their use and they will embed their values and predispositions in these new technologies. This means that the resulting strategies will be as diverse as the pre-existing differences between organizations.

On the basis of this discussion of these two bodies of literature we can formulate two contradicting expectations:

Expectation 1. Social media strategies of police departments will be similar since these technologies facilitate certain external communication practices.

Expectation 2. Social media strategies of police departments will be different since pre-existing differences in communication strategies are reinforced.

These expectations are rather extreme in these sense that they propose it is either technology or the organization that matters. An intermediate perspective argues that the confrontation of technology and organization results in strategies that are influenced both by technological features and by organizational characteristics. This intermediate approach is supported by many empirical studies into technology and organization (Nardi \& O'Day, 1999; Williams \& Edge, 1996). Still, the 'naïve' expectations are valuable to assess to what extent technological characteristics matter and whether social media indeed have a transformative potential.

\section{Research methods}

The case studies aim to test the two expectations by reconstructing the emerging social media strategies of three North American police departments. Studying an emerging strategy means analyzing both the introduction of social media in police departments and their subsequent embedding in organizational routines. The empirical analysis starts with an analysis of the introduction of social media in the organization in terms of (1) the technological form of the introduction, (2) the organizational position of the actor that introduced the social media in the organization, (3) the linkage to a specific task and (4) the expected benefits of social media usage. The path of development is studied that eventually results in the current practices and cognitions. These will also be used in terms of our four elements: (1) technological choices, (2) coupling to organizational tasks, (3) objectives of social media use and (4) a set of organizational arrangements. Similarities and differences between these social media strategies are analyzed.

The paper is based on qualitative empirical research at the Boston Police Department, the Metropolitan Police Department (Washington DC) and the Toronto Police Service. We chose to do our research within police departments because they resemble each other in terms of the tasks they have to fulfill within society. Also the way police departments are organized and structured is more or less quite similar. These similarities are crucial to conducting comparative research. The three departments were selected as most advanced practices in terms of their use of social media for supporting the police and, as a consequence, the results aim to enhance our theoretical understanding of the (lack of) variation social media strategies (cf. Eisenhardt, 1989; Yin, 1984). The selection of the police departments of Boston, Washington and Toronto was based on our own investigation into police departments that were actively and visibly using social media applications. We used a review of the literature and a broad scan of internet practices. These three departments came forward as being among the frontrunners in the use of social media. The results of these case studies can be no means generalized to other police departments in North-America since their level of social media usage is generally lower than in the three departments that we have investigated.

The case studies in the three major cities consisted of interviewing, document analysis and an analysis of social media use. Interview questionnaires were based upon our conceptualizations of social media strategies and focused on reconstructing both current practices and their origins. These questionnaires were developed around the following topics:

- Start of the use of social media within the department. Since when are social media used? What was the trigger that initially led to the use of social media?;

- Main objectives for its use. What were the main objectives? Were these objectives stable over a longer period of time? Was there a shift in objectives over time?;

- Experiences of the department with the use of social media. How are social media used and has the department developed a policy for the use of these media?;

- Results and the way in which success is defined within the department. Did the department reach its objectives? What have been the effects of the use of social media on the effectiveness and legitimacy of the department? Does the department evaluate the success of its social media use?;

- Organizational aspects. How has the organization reacted to the use of social media? Is the management of the department involved? Who is responsible within the department for the use of social media?;

- Operational aspects. How is the use of different kinds of social media organized? Are there criteria for the use of social media? Who within the department makes decisions about operational aspects of the use of social media? Does privacy play an important role in the decision-making process?

- Tuning of the activities. Was or is there any contact about the use of social media with other police departments or other organizations? What is the prediction about the further development of the use of social media within the department?

We carefully selected the key players for social media strategies in the three departments and interviewed them extensively. The interviews generally took 2 to $3 \mathrm{~h}$ and covered all aspects of their social media strategies. With such a research method there is always a risk that the case descriptions are biased by the perspective of the informants. We have used triangulation to strengthen our findings: in addition to the interviews we have used document study and observations of social media usage (blogs, Twitter accounts, Facebook postings). For pragmatic reasons, we did not study citizens' perceptions. This can be seen as a limitation of the research because the claimed effectiveness of these strategies is not tested. This is acceptable since the analysis focuses on the nature of the strategies and the reasons for choosing a specific strategy.

In Boston, interviews were conducted with the Head of Corporate Communications and the Chief Technology Officers. Additional 
information was obtained through conversations with the Dignitary Protection Security Coordinator. In Washington DC interviews were conducted with an IT specialist, the Coordinator of the Volunteer Services, the Commander of the Police Information Center and a Marketing Specialist. Two interviews were conducted at the Toronto Police Service with one of the pioneers of their social media program and the current head of Corporate Communications. Documents, websites and social media presence - Twitter, YouTube, Facebook and blogs - of the three departments were analyzed in addition to the interviews.

\section{Research findings}

\subsection{Boston Police Department: push strategy}

In the beginning of the 21st century the Boston Police Department (BPD) has a bad coverage in the press. R2 at BPD: 'The media were competing every day to write the worst possible stories about the BPD. This was affecting our reputation with the communities. It also affected officer moral.' One reason for them to write these stories is that the media felt that the BPD was not informing them: 'They were angry because they were not getting information from the BPD.' The Communication Department identified the development of a 'better brand' as the key challenge for their media strategy. Social media turned out to be a useful instrument for tackling that challenge.

The use of social media by BPD started with an administrative problem: the Chief Technology Officer wanted to start a website but the City of Boston did not allow this. He decided to bypass formal procedures and create their own website: BPD News. The website was developed with the use of generally available open technology and without any funding from the police department. The website was used to create a direct channel between the police department and citizens. The Head of the Corporate Communications told her people: 'I want you to think like a public safety outlet. We are not communicating with journalists but with people.' In the beginning, misinformation was the major issue. R2 at BPD: 'The blog enabled us to correct mistakes in the coverage.'

BPD News slowly evolved into a broader communication platform. People asked questions to community officers about crime stats and citizen alerts and this information became part of BPD News. BPD News evolved from a blog into a 'one stop shopping for community safety news'. When the information on BPD News expanded, Corporate Communications also started raising more public interest for BPD News. They put it on posters and on the side of every cruiser. Their public rapidly expanded. R2 at BPD: 'We could tell from the stats and we heard from the community that people were reading it. And not only 'good citizens' were reading it. Suspects wanted to know who in their neighborhood was in trouble.'

BPD News is still the heart of external communications through new media but it is now used in connection with other social media such as Twitter, YouTube and Facebook. In the beginning Corporate Communication was hesitant to start using Twitter since it could spread and fragment communication efforts but they became quickly convinced of the additional value. These social media were first used for RSS feeds of BPD News but this turned out not to be effective. Now Facebook is used in the 'Facebook way' and Twitter in the 'Twitter way'. R2 at BPD: 'The number of retweets went up enormously.' The BPD has only one Twitter account and this is managed by Corporate Communications. R2 at BPD: "I don't think our confidence level is so high that we want individual officers to broadcast communications. Things would be out of control. There needs to be a balance between the message and enabling communication. We want to prevent them from making large and public mistakes."

Twitter is the only channel where people can publish who are not with Corporate Communications, for example information from the 911 Center on shootings and traffic accidents but this communication is monitored to make sure it is in line with corporate standards.
The respondents at BPD acknowledge that social media communicate a personality to the community but in the case of the BPD this is an organizational or composite personality. Employees at Corporate Communication never communicate as individuals. Twitter is sometimes used for crowd control. When large groups of college students went to the Boston Common at 3 o'clock in the morning to celebrate that Osama Ben Laden had been killed the BPD sent out a tweet with the text 'Honor our troops respectfully!'

YouTube is not used much for investigations. R2 at BPD highlighted that the district-attorney often doesn't want us to bring it out since it may hinder an investigation. In addition, detectives want to do other things first and do not want to receive many tips that they need to look into while they already know they are probably not useful. There are pictures of Most Wanted Criminals on BPD News. YouTube is mainly used for promotional material and press conferences but also recordings of police graduations to enable relatives at home to view this event.

This case description shows how the Boston Police Department uses social media mainly for corporate branding which had become the main focus in their communication strategy. Social media communication results in more transparency of police activities as a strategy to 'disintermediate' (Edwards, 2006) the mass media. This can be qualified as a 'push strategy' (Mergel, 2010): social media are used to 'push' information to citizens and not to obtain information from them. The use of social media started in a collaboration between the Chief Technology Officer and Corporate Communications and builds upon a previously existing strategy of centralized contacts with the media. Corporate Communication has chosen to control the use of social media and individual officers are not allowed to use them. The use of social media to support specific police tasks is limited although it is used to some extent for better collaboration and new forms of public participation through community outreach and crowd control.

\subsection{Metropolitan Police Department (Washington DC): push E pull strategy}

The start of social media usage with the Metropolitan Police Department in Washington DC (MPDC) was closely related to specific tasks. MPDC started with the use of YouTube around 2009. YouTube was used for recruiting volunteers but also for investigative purposes. Since the department started using social media the number of volunteers that applied for a function has more than doubled. R1 mentioned, as an example of the use of YouTube for investigative purposes, a shooting in the subway. Cameras within the train have registered this shooting and this footage was placed on YouTube. This was very effective: much relevant information was provided by citizens and within $12 \mathrm{~h}$ this crime was solved. Since the end of 2011 the department has its own YouTube channel for posting videos. In the starting period, it was not possible for citizens to react on a movie using YouTube. This option was not used by the MPDC mainly because of the fear that this would lead to all kinds of nonsense and also phony reactions. At this moment the option to react on YouTube is enabled. SBB monitors these reactions. If there is a reaction that perhaps could be useful, this reaction is forwarded to a detective that is on the case.

In parallel, the Metropolitan Police Department in Washington DC (MPDC) started using Twitter for an acute reason: the occurrence of an earthquake in 2010. The MPDC realized that Twitter could help them to get information out more quickly to citizens than before. This social medium was used as an additional means and the police department felt that it was quite useful for immediate communication with citizens in a crisis situation. The origins of Facebook usage are not directly connected to a special area of police activity. On the Facebook page of MPDC tweets are repeated and press releases are published. Furthermore, it is used for the publication of news articles and releasing additional information to the public. These three forms of social media use have received broad support from the Police Chief. Since her appointment in 2007, the Chief of Police has stimulated the use of social media within 
the department. She favors openness and transparency and considers Facebook and Twitter as priorities. She herself is not active on Twitter, but she does have her own page on Facebook.

The fact that the MPDC's social media strategy originated in supporting specific tasks has resulted in another strategy than in the other two police departments. Communication goals like strengthening the image of the department and building good relations with citizens are considered to be of value but more important is the direct contribution to police tasks. The respondents highlighted goals such as crisis management, the detection and prevention of crimes and also the recruitment of new officers.

Social media are not managed by Corporate Communication but by the Strategic Services Bureau (SBB). More specifically, Twitter is managed in the control room. This is where all emergency situations are handled and Twitter is regarded as a suitable means for emergency communications. The department works with a central Twitter account. This means that a selected group of officers is allowed to use this account for sending out tweets. The idea behind this central account is the need to be in control over the communication that takes place from the department with the outside world. According to R2 at MPDC: "A choice to use Twitter accounts for each unit within the organization, could lead to possible confusion among citizens". Following this policy, police officers on the street are not allowed to use Twitter.

The group that is allowed to use this central Twitter account consists of staff of the Command Information Center, the top level managers within the department and supervisors at the command staff. The group consists of about 35 persons. Each of them is trained in how to use Twitter and they are all aware of the essential protocols that are involved in using social media. As part of the control over Twitter, the Command Information Center reads all the tweets and has to approve them before they are published. However, to make the use of Twitter more personal, each tweet shows the unique badge number of the officer that composed the tweet. According to R1 at the MPDC Twitter is mainly seen as a way "to convey information from the department to the public". Reactions from citizens on tweets from the police are monitored. However, it is not the primary goal of the use of Twitter to receive these reactions. For reporting crimes, for example, it is preferred that citizens use other media to contact MPDC since Twitter is seen as relatively unreliable source of information.

When YouTube, Twitter or Facebook is used for crime investigations, a so called 'event number' is incorporated in the message. If, as a reaction to this message, a citizen reports information about the crime, then he or she will be asked for this event number. It is also recorded in the registration system that is used within the call center. In everyday practice investigation messages are broadcasted using many media at the same time. Not registered is whether a citizen is triggered to contact the police after he or she has seen a message on Facebook, a tweet on Twitter or a video on YouTube. Furthermore, citizens also use different media for (anonymous) contacting the police. Most used are the telephone and sending text messages.

As indicated above, in Washington a mix of media is used with regard to social media. If a video is uploaded on the YouTube channel, then a Tweet is broadcasted to attract citizens' attention for this new video. Also a traditional press release is distributed after a video has been put online. Facebook is used for a repost of tweets and for the publication of press releases, news articles and for the distribution of other types of information. The police aim to enhance the synergy between these different media channels.

The case description highlights how the MPDC has developed a multimedia mix and they have positioned Twitter, YouTube and Facebook in the mix. Their strategy can be qualified as a 'push and pull strategy': they use social media to provide citizens with information but also to get specific information from citizens. Twitter creates some transparency and strengthens citizen participation by enabling them to provide time critical information to the police. The social media that emerged from their application are specific tasks and they are still directly related to these tasks: police investigations, recruiting volunteers and direct communications with citizens from the control room. The Strategic Services Bureau holds the overall responsibility but the specific media are managed by the responsible unit, e.g. the Control Room manages Twitter. The overall objective of social media use is to enhance police effectiveness by using better instruments to execute tasks.

\subsection{Toronto Police Service: networking strategy}

In 2007, the Toronto Police Service (TPS) was the first Canadian police department to start using social media on a structural basis. The initiative to use social media was taken by a police officer who was stationed from the Toronto Police as a Youth Outreach Officer at the local branch of Crime Stoppers to encourage students with information about criminal activities to call Crime Stoppers. ${ }^{1}$ R1 at TPS: 'His basic message to youths was: the police are your friend. Report crime!' The social media that were used in the beginning were Twitter, Facebook and YouTube and these were primarily used to contact a target group that has traditionally been hard to reach: young people in urban areas. The police officer that started this initiative used a Twitter handle that is meant to be meaningful to this target group: @GraffitiBMXcop. He made an effort to build relationships with people and offline and online contacts complimented one another: use of social media amplifies offline efforts.

Two years after this first initiative, in 2009, another police officer started using social media for another police function: traffic services. The primary goal of traffic services is to raise the awareness of citizens that they need to adhere to traffic rules. To contribute to this objective, the officer started with a blog, Twitter (@TrafficServices), Facebook (http://www.facebook.com/TrafficServices) and YouTube. He provided information about accidents to bring the message across that people should wear seatbelt to save lives. Traffic communications were not only about informing citizens. Respondent 1 at TPS: 'It was two-way communication. If we got requests from citizens about where to do the enforcement for speeding, we'd go there and do the enforcement.' The police officer also developed three channels at YouTube: Collisions, Safety Program and General Information. These channels were filled with material from accidents in Toronto but also from other police departments worldwide. The message he wanted to communicate was to drive safely.

These bottom-up initiatives were noticed and supported by top management at the TPS. Top management decided to move the use of social media to a higher level after the two police officers had been invited to present their work on a North-American conference on police and social media use. The two police officers were transferred to Corporate Communication and invited to develop a corporate presence on social media. A consultant was hired to help them to develop a social media strategy and this strategy was formally approved in 2011. This meant that funding became available to roll the use of social media out in the TPS and the social media strategy was formalized in a document (Toronto Police Service, 2011, Social Media Strategy).

The current social media strategy of the TPS is based upon the idea that individual officers and also the various divisions have their own responsibility for using social media. R2 at TPS: 'Social media means giving up some of that control. That is a huge challenge. People ask: Are you going to authorize every tweet? No. You give up control.' R2 at TPS highlighted that this strategy of individual responsibility builds upon a general communication strategy that had been introduced seven years ago. The new police chief wanted 'authentic communication' and therefore preferred to have a variety of (black/white,

\footnotetext{
1 Crime Stoppers (http://csiworld.org/) is a worldwide non-profit organization that enables citizens to send tips to the police anonymously. Citizens get a number and if their tip is used to solve the crime they can use this number to obtain money for this tip. Crime Stoppers works at arm's length of the police and has an own board of directors.
} 
Table 3

Overview of the social media strategies.

\begin{tabular}{|c|c|c|c|}
\hline & Boston: push strategy & Washington DC: pull strategy & Toronto: networking strategy \\
\hline Technological choices & $\begin{array}{l}\text { A central platform, the blog site } \\
\text { BPD News and in addition } \\
\text { Twitter are used }\end{array}$ & $\begin{array}{l}\text { A multimedia mix is used to create synergy } \\
\text { between Twitter, YouTube and Facebook. }\end{array}$ & $\begin{array}{l}\text { A variety of options: Twitter, } \\
\text { Facebook and YouTube are } \\
\text { used separately }\end{array}$ \\
\hline Organizational tasks & $\begin{array}{l}\text { Limited set of tasks: mainly public information } \\
\text { and some community outreach } \\
\text { and crowd control }\end{array}$ & $\begin{array}{l}\text { Limited set of tasks: focus on police investigations, } \\
\text { recruiting volunteers and control } \\
\text { room communications }\end{array}$ & $\begin{array}{l}\text { All tasks: officers and divisions } \\
\text { cater the social media } \\
\text { to their tasks. }\end{array}$ \\
\hline Objectives & Improve the corporate brand of the BPD. & $\begin{array}{l}\text { Enhance the effectiveness of the police } \\
\text { by using better instruments } \\
\text { for specific tasks }\end{array}$ & $\begin{array}{l}\text { Humanizing the police and } \\
\text { enhancing effectiveness by better } \\
\text { interactions with specific } \\
\text { citizen groups }\end{array}$ \\
\hline Organizational arrangements & $\begin{array}{l}\text { Centralized arrangement: } \\
\text { Corporate Communications controls } \\
\text { external communications } \\
\text { via social media }\end{array}$ & $\begin{array}{l}\text { Centralized arrangement: Strategic Services } \\
\text { Bureau holds overall responsibility. }\end{array}$ & $\begin{array}{l}\text { Decentralized arrangement: responsibility } \\
\text { lies with the officials that } \\
\text { use social media. }\end{array}$ \\
\hline
\end{tabular}

male/female, old/young) police officers to talk to the media than just two or three public information officers.

Corporate Communications helps the divisions to develop strategies but they need to ensure that the use of social media contributes to the realization on the division's objectives. Training police officers to use social media is the core activity in the Social Media Program. Corporate Communications has developed a three day training program and 200 officers have been trained between July 2011 and January 2012. They're trained to use social media, to experiment with them, to adapt them to their own tasks but also to abide by certain rules such as 'don't speculate', 'don't talk about the investigation' and 'don't talk about agents'. After the training their social media behavior is monitored and coaching is provided. The aim is to train a total of 250 people out of 8000 employees at the Toronto Police Service. R1 at TPS: 'The ones that have been trained can now be ambassadors for the use of social media. It can spread through the organization.'

Specific features of the social media strategy are "humanizing the police' and 'narrowcasting'. The Communication Department highlights that social media communication should be used to 'humanize' an impersonal and therefore possibly frightening institution. R1 at TPS emphasizes that humor is important and mentioned the following example. 'People would say: $\mathrm{O}$ my God. I am being followed by the Toronto Police. I tweeted: I am behind you and checking your signals.' R2 at TPS highlighted that social media makes narrow casting an option: 'The internet creates the ability to go directly to target audiences and not have it filtered by the media. It is faster, more efficient and enables us to engage in a two way dialogue. The elderly are a specific group of interest. On Facebook the older groups are among the fastest growing groups. One of the big areas is fraud against the elderly. The idea is to engage with an online community to prevent crime.'

This case description shows how the Toronto Police Service (TPS) builds upon a previously existing strategy of individual contacts with the media. The resulting strategy can be qualified as a 'networking strategy' (Mergel, 2010): social media are used to build networks between individual police officers and citizens. Bottom-up initiatives with social media were embraced and given support by the police chief. The department has chosen to facilitate and support the use of social media by divisions and individual officers. The main objective is to build better (long-term) relations between police and citizens that contribute to transparency, police legitimacy and the realization of a wide variety of tasks such as apprehending criminals but also improving traffic safety.

\section{Analysis: dimensions and configurations}

Looking at the three cases, we see that each department uses social media to increase the effectiveness and legitimacy of their own organization. All three departments are using social media to increase transparency, to support inter- and intra-organizational collaboration and to enable innovative forms of public participation and engagement. They all are looking for new ways to communicate with citizens and to reach more citizens then is the case without the use of social media applications. Another similarity is that the use of social media within the three cases is not limited to a specific social media application. In all three departments different kinds of social media applications Twitter, YouTube and Facebook - are used at the same time and they are all struggling with ways to position these media in an overall strategy.

Despite the similarities, the social media strategies of the three departments differed widely. The emerging social media strategies of the three police departments have been presented in the case descriptions. The main features of these social media strategies are summarized in Table 3 below.

The table shows that the social media strategies of the three police departments differ on all dimensions. These dimensions are not independent: the variations form three different configurations that are consistent combinations of technologies, tasks, objectives and organizational arrangements. The positioning of social media results in different choices in terms of the number of accounts (one account in Boston and Washington and a large number of accounts in Toronto) and also in terms of who is responsible for external communications (the communication department in Boston and individual police officers in Toronto and Washington). The strategic positioning also means that individual training is a top priority in Toronto and to a lesser extent in Washington while the BPD emphasizes the rules that restrict the individual use of social media by police officers.

The three different configurations can be labeled as follows:

- Push strategy to strengthen the police image. The Boston Police Department (BPD) uses social media to improve its public image. Social media enable the police to communicate directly with citizens and to bypass established media outlets. The BPD has used social media to develop its own media outlet and to refocus the attention of the public not only on the shortcomings of safety in Boston but also on police successes.

- Push \& pull strategy to inform citizens and improve citizen-input in (time critical) police investigations. The Metropolitan Police Department (MPD) uses social media to provide information and obtain fast information from citizens about crimes, critical situations, wanted and missing persons. The objective is not to build longer relationships but to engage citizens as the eyes and ears of the police.

- Networking strategy to build better police-citizen relations. The Toronto Police Service (TPS) uses social media to build better long-term relations between police and citizens. The TPS believes that this can be realized by enabling authentic, individual external communication by police officers. This type of communication is expected to result in better police-citizen relations at the local level and strengthen community policing. 
The fact that we found three of Mergel's (2012) strategies in our three cases is a strange coincidence since we did not select the cases on the basis of her typology. These cases were selected as best practices in terms of social media use by North American police departments. Our findings do not show that Mergel's typology is exhaustive neither do they show that these models are equally distributed over the public sector. The findings prove nothing more (or less) than that these strategies exist in practice. More systematic research is needed to show whether the typology covers all strategies and how they are distributed over the whole population.

The differences in these strategies can be explained on the basis of the context of the social media use within the police ( situational characteristics) and the initial start of social media usage (path dependency) (Nardi \& O'Day, 1999; Williams \& Edge, 1996). Situational characteristics such as the hostile media environment in Boston explain why this police department was much more hesitant to facilitate individual communication than the Toronto Police Service. A key situational characteristic is the overall communication strategy. The cases show how both the decentralized strategy in Toronto and the centralized strategy in Boston and Washington DC were reproduced in the social media strategy. The path dependency proved specifically important in Washington DC where the start of social media usage outside of Corporate Communications accounts for a strong relation between social media use and the execution of specific tasks. Interestingly, in Toronto social media use also started outside Corporate Communications but it was repositioned within this department later on. Still, the features of a focus on specific police tasks are present in Toronto's social media strategy and this can partly be attributed to the path of development that started outside Corporate Communications. This shows that an analysis of situational characteristics and the path of development can help us to understand emerging strategies but due to the complex interrelations between various factors this type of analysis cannot provide a causal explanation.

\section{Conclusions: a transformation requires fertile soil}

We started this paper with the following question: do police departments develop similar or different social media strategies and how can similarities or differences be explained? This question can be answered by testing the two expectations on these bases of our case studies. Our first expectation stated that social media strategies of police departments will be similar since these technologies facilitate certain external communication practices. There were some general references to media requirement such as being rather informal on Twitter but in terms of content the social media usage was quite different. There were more similarities in the use of YouTube, for example for police investigations and public promotion, but there were also substantial differences here. YouTube use for recruiting volunteers was important in Washington DC but this form has not yet been explored by the other departments. Overall, we found limited support for the expectation that the use of new technologies would result in what DiMaggio and Powell (1983) refer to as 'organizational isomorphism' or convergence of organizational forms.

Our second expectation stated that social media strategies of police departments will be different since pre-existing differences in communication strategies are reinforced. As we have already discussed the differences, it is clear that we did find support for this expectation. Police departments make different choices in terms of who can use social media, how they can use social media and what the objectives of the use of social media are. These choices reflect the differences between police departments such as the decentralized media strategy in Toronto and the emphasis on branding in Boston. Apart from this, we found that differences in social media strategies also emerge because of the unpredictable dynamics of the specific (bottom-up or top-down) process that the introduction of social media takes within the organization.
Our research provides only very limited support for the transformational potential of social media. The discourse about the user-generated state does not appear to be in line with actual developments: government organizations do not develop radically different relations with citizens through social media. Although all police departments use social media to increase transparency, to support inter- and intra-organizational collaboration and to enable new and innovative forms of public participation and engagement, the empirical study shows how social media is a new instrument that is encapsulated in previously existing routines and organizational arrangements. The three case studies clearly highlight how the social media with their participation 'logic' are adapted to current organizational arrangement and policing strategies. In contrast with the expectations of some of the digital age gurus (Eggers, 2005; Leadbeater \& Cottam, 2009), we found no support for the emergence of 'user-generated policing'.

In line with King and Kraemer's (2012) argument about reinforcement, we would like to present the following revised hypothesis for social media strategies in government:

Revised expectation. Social media strategies of police departments build upon pre-existing strategic choices in communication strategies and situational differences and therefore, in spite of access to similar technologies, conversion in these strategies is limited.

This revised expectation needs to be tested in more encompassing research on social media in the public sector and including a broader set of government organizations.

The exploratory study shows that the only police department that has developed some kind of 'user-generated policing' is the Toronto Police Service. The analysis highlights that their openness towards decentralized citizens input had been started before these new media were introduced and, in that sense, social media can hop on the bandwagon. The Boston and Metropolitan Police Departments have more traditional social media strategies to match their organizational routines based on formalization, hierarchy and centralization. The Toronto Police Service has already acknowledged the value of decentralized communications between police and society and the importance of building (horizontal) networks between individual police officers and citizens and, therefore, the organization was more open to a networking strategy for social media. We conclude that the social media logic only manifests itself if it lands on fertile soil in a government bureaucracy.

\section{References}

Bertot, John C., Jaeger, Paul T., \& Grimes, Justin M. (2010). Using ICTs to create a culture of transparency: E-government and social media as openness and anti-corruption tools for societies. Government Information Quarterly, 27, 264-271.

Bertot, J. C., Jaeger, P. T., \& Grimes, J. M. (2012). Promoting transparency and accountability through ICTs, social media, and collaborative e-government. Transforming government: People, process and policy, 6, 78-91.

Bertot, J. C., Jaeger, P. T., \& Hansen, D. L. (2012). The impact of policies on government social media usage: Issues, challenges, and recommendations. Government Information Quarterly, 29, 30-40.

Bretschneider, S. I., \& Mergel, I. (2010). Technology and public management information systems: Where have we been and where are we going. In D. C. Menzel, \& H. J. White (Eds.), The state of public administration: Issues, problems and challenges (pp.187-203). New York: M.E. Sharpe, Inc.

Chaffee, E. (1985). Three models of strategy. Academy of Management Review, 10, 89-98.

Choon, S. A., \& Luna Reyes, L. F. (2012). Social media in government. Government Information Ouarterly, 29, 441-445.

Dadashzadeh, M. (2010). Social media in government. From eGovernment to eGovernance. Journal of Business E' Economics Research, 8, 81-86.

Danziger, J. N., Dutton, W. H., Kling, R., \& Kraemer, K. L. (1982). Computers and politics. New York: Columbia University Press.

Deibert, R. D. (1997). Parchment, Printing and Hypermedia. New York: Columbia University Press.

DiMaggio, P. J., \& Powell, W. (1983). The iron cage revisited institutional isomorphism and collective rationality in organizational fields. American Sociological Review, 48, $147-160$.

Edwards, A.R. (2006). ICT strategies of democratic intermediaries: A view on the political system in the digital age. Information Polity, 11, 163-176.

Eggers, W. D. (2005). Government 2.0: Using technology to improve education, cut red tape, reduce gridlock, and enhance democracy. Lanham, Maryland: Rowman \& Littlefield Publishers, Inc. 
Eisenhardt, K. M. (1989). Building theories from case study research. The Academy of Management Review, 14, 532-550.

Fountain, J. E. (2001). Building the virtual state. Information technology and institutional change. Washington DC: The Brookings Institute.

Hrdinová, J., Helbig, N., \& Peters, C. S. (2010). Designing social media policy for government: Eight essential elements. Albany, NY: Center for Technology in Government.

Kavanaugh, A. L., Fox, E. A., Sheetz, S. D., Yang, S., Li, L. T., Schoemaker, D. J., et al. (2012). Social media use by government: From the routine to the critical. Government Information Quarterly, 29, 480-491.

King, J. L., \& Kraemer, K. L. (2012). Too early to say. In I. Snellen, M. Thaens, \& W. van de Donk (Eds.), Public administration in the information age: Revisited (pp. 281-295). Amsterdam: IOS Press.

Kraemer, K. L., \& King, J. L. (2006). Information technology and administrative reform: Will e-government be different? International Journal of Electronic Government Research, 2, 1-20.

Landsbergen, D. (2010). Government as part of the revolution: Using social media to achieve public goals. Electronic Journal of eGovernment., 8, 135-147.

Leadbeater, C., \& Cottam, H. (2009). The user-generated state: Public Services 2.0. Available at: www.charlesleadbeater.net/archive/public-services-20.aspx (accessed 3 December 2012)

Ma, L. (2013). Diffusion and assimilation of government microblogging. Public Management Review, http://dx.doi.org/10.1080/14719037.2012.725763.

McLuhan, M. (1964). Understanding media: The extensions of man. New York: McGraw Hill.

Meijer, A., Koops, B. J., Pieterson, W., Overman, S., \& Ten Tije, S. (2012). Government 2.0: Key challenges to its realization. Electronic Journal of e-Government, 10, 59-69.

Meijer, A., \& Thaens, M. (2010). Alignment 2.0: Strategic use of new internet technologies in government. Government Information Quarterly, 27, 113-121.

Mergel, I. (2010). Government 2.0 revisited: Social media strategies in the public sector. PA Times, 33( 7 \& 10).
Mergel, I. (2012). The social media innovation challenge in the public sector. Information Polity., 17, 281-292.

Mergel, I., Mugar, G., \& Hossein Jarrahi, M. (2012). Forming and norming social media adoption in the corporate sectorProceedings iConference 2012, February 7-10 Toronto, Canada.

Mintzberg, H. (1978). Patterns in strategy formation. Management Science, 24, 934-948.

Mintzberg, H., \& Waters, J. A. (1985). Of strategies, deliberate and emergent. Strategic Management Journal, 6, 257-272.

Nardi, B.A., \& O'Day, V. L. (1999). Information ecologies. Using Technology with Heart. Cambridge MA: MIT Press.

Orlikowski, W. J. (1992). The duality of technology: Rethinking the concept of technology in organizations. Organization Science, 3, 398-427.

Picazo-Vela, S., Gutierrez-Martinez, I., \& Luna-Reyes, L. F. (2012). Understanding risks, benefits, and strategic alternatives of social media applications in the public sector Government Information Quarterly, 29, 504-511.

Porter, M. E. (1980). Competitive strategy. New York: The Free Press.

Snead, J. T. (2013). Social media use in the U.S. Executive Branch. Government Information Quarterly, 30, 56-63.

Wigand, F. D. L. (2011). Tweets and retweets: Twitter takes wing in government. Information Polity, 16, 215-224.

Williams, R., \& Edge, D. (1996). The Social Shaping of Technology. Research Policy, 25 865-899.

Yin, R. (1984). Case study research. Beverly Hills, CA: Sage Publications.

Albert Meijer (1967) is an associate professor at the Utrecht School of Governance. His research focuses on transparency, coproduction and social media.

Marcel Thaens (1968) is a professor of public administration at Erasmus University Rotterdam. His main research interests are strategy and innovation. 